\title{
LA ATENCIÓN SANITARIA INFANTIL COMO PREOCUPACIÓN EDUCATIVA
}

\author{
Núria Padrós \\ Universidad de Vic - Universidad Central de Catalunya \\ nuria.padros@uvic.cat \\ Pilar Prat \\ Universidad de Vic - Universidad Central de Catalunya \\ pilar.prat@uvic.cat \\ Eulàlia Collelldemont \\ Universidad de Vic - Universidad Central de Catalunya \\ eulalia@uvic.cat
}

\section{RESUMEN}

El análisis de la normativa oficial nos permite proponer la hipótesis de estudio que la atención sanitaria infantil ocupó un lugar predominante en las preocupaciones educativas de la primera mitad del siglo XX en España. Para realizar la investigación nos hemos centrado en analizar los filmes de propaganda educativa que se realizaron en este contexto. Concretamente, hemos secuenciando aquellos elementos de forma y de contenidos que aparecen en los filmes. En este artículo se presentan los resultados de la investigación llevada a cabo para contrastar dicha hipótesis. ${ }^{1}$

Palabras clave: Atención sanitaria infantil. Análisis de filmes. Propaganda educativa.

\section{CHILDREN'S HEALTHCARE AS AN EDUCATIONAL CONCERN}

\begin{abstract}
The analysis of official regulations allows us to propose the hypothesis that the children health care occupied a prominent place in the educational concerns of the first half of the twentieth century in Spain. To do the research we have focused our attention in the analysis of the educational propaganda films that were made in this context. Specifically, we have sequenced the formal elements and on the content which appear in the films. This article presents the results of the research conducted to contrast this hypothesis.
\end{abstract}

Keywords: Childhealthcare. Film analysis. Educational propaganda.

\section{A SAÚDE DA CRIANÇA COMO PREOCUPAÇÃO EDUCACIONAL}

\section{RESUMO}

A análise dos regulamentos oficiais nos permite formular a hipótese de que os cuidados de saúde da criança tiveram um lugar destacado nas preocupações educacionais da primeira metade do século XX na Espanha. Para realizar a pesquisa, têm-se centrado na análise dos filmes de propaganda educacionais que foram feitas neste contexto. Especificamente,

\footnotetext{
${ }^{1}$ Este artículo está realizado al amparo del proyecto del Ministerio de Economía y Competitividad Revisión y Análisis de Documentales Propagandísticos y Anuncios Audiovisuales Educativos producidos entre 1914-1939 En España. (Ref. EDU2013-48067-R)
} 
sequenciaram os elementos do forma e do conteúdo que aparecem nos filmes. Este artigo apresenta os resultados da pesquisa realizada para contrastar esta hipótese.

Palavras-chave: Cuidados na saúde da criança. Análise de filmes. Propaganda educativa.

\section{ENFANT DE SOINS DE SANTÉ EN TANT QUE PREOCCUPATION POUR L'EDUCATION}

\section{RÉSUMÉ}

L'analyse de la réglementation officielle nous permet de proposer l'hypothèse selon laquelle de soins de santé de l'enfant ont occupé une place importante dans les préoccupations éducatives de la première moitié du XXe siècle en Espagne. Pour mener cette recherche, nous avons mis l'accent sur l'analyse des films de propagande éducatifs qui ont été faites dans ce contexte. Plus précisément, nous avons séquencé les éléments de forme et de contenu des films. Cet article présente les résultats de la recherche menée pour contraster cette hypothèse.

Mots-clés: Attention sanitaire enfantine. Analyse des films. Propagande éducative.

\section{INTRODUCCIÓN}

En el presente artículo presentamos un análisis de los films de propaganda educativa de inicio del siglo XX realizados en España. En este contexto, es importante destacar que cuando uno se acerca a la propaganda producida a inicios de siglo en la que aparecen como protagonistas los niños y niñas, se percata rápidamente del entrelazamiento que había entre los temas sanitarios y los temas educativos. Este vínculo no es de extrañar pues se inscribe en el interés para mejorar la salud de la población en general que, aunque empezó a finales del s.XIX, adquiere más relevancia en España a partir de 1904 con la publicación de la Instrucción General de Sanidad y se consolida durante las décadas de 1920 y 1930.Aunque en un primer momento los canales propagandísticos serán, básicamente, charlas y escritos, pronto el cartelismo, la radio y el cine verán incrementada su importancia como herramientas de difusión (MOLERO, 1989; PERDIGUERO, 2008).

La mejora de la vida infantil (cuyo panorama según los datos que se disponen era desolador) se convirtió en un objetivo prioritario para diferentes agentes sociales que impulsaron diversos programas que contemplaban acciones de propaganda destinadas a cambiar las costumbres y formas de vida de las familias y de los profesionales e instituciones dedicadas a la infancia. En el presente escrito nos centraremos en las acciones que tenían como medio los documentales publicitarios.

Con el objetivo de comprender cómo se estaba desarrollando la génesis de la atención a la infancia, hemos realizado una aproximación a los films que fueron producidos 
con anterioridad a la Guerra Civil Española, y que, según nos consta por los estudios realizados, se inscribían en la reciente tradición europea y americana de acceder a la población mediante este nuevo medio de comunicación que permitía integrar los avances de la propaganda publicitaria visual con la textualidad narrativa (primero, expresada mediante rótulos y, posteriormente, con voces sonoras).

De las campañas publicitarias del período analizado que escogieron el audiovisual como medio para llegar a la población, se conservan hoy en día en las Filmotecas Española, de Valencia (el IVAC) y de Catalunya los siguientes films:

- Valencia protectora de la Infancia de Maximiliano Thous de 1928

- El Segell Pro-Infància producida por la Generalitat de Catalunya, producida entre 1934 y 1935

- Vidas Nuevas de Julio Bravo de 1936

Documentales que han sido analizados para elaborar el presente artículo. A continuación se presentan, de forma breve, el contexto de realización de cada uno de los films, sus características técnicas y un resumen de su contenido.

\section{EL FILM "VALENCIA PROTECTORA DE LA INFANCIA"}

En cuanto al contexto del documental Valencia protectora de la Infancia se debe situar en medio del período de la dictadura de Primo de Rivera (1923-1931). En esta etapa se realizaron diferentes reportajes propagandísticos de la labor del gobierno así como de la modernidad de las instituciones españolas. Habitualmente $-\mathrm{y}$ con excepción del fragmento dedicado al Cervantes de Madrid de ¿Qué es España?-, estos films se caracterizaban por mostrar más los 'entornos educativos' que, propiamente, la vida infantil.

Sin embargo, podemos considerar una excepción al reportaje Valencia, protectora de la infancia puesto que en él aparecen distintas escenas retratando la vida de niños y niñas. Esta película, producida por Maximiliano Thous, se realizó por encargo de diferentes administraciones valencianas $^{2}$ para participar en la Quincena Internacional de protección de la Infancia y Acción Social celebrada en París en julio de 1928, creándose para ello dos versiones: la que habría de exponerse en España y la que se visionaría en París.

\footnotetext{
${ }^{2}$ Concretamente, la Junta Provincial de Protección a la Infancia, con la colaboración del Ayuntamiento y la Diputación Provincial de Valencia.
} 
A día de hoy, una copia del documental se halla en la Filmoteca de Valencia, institución que ha promovido su restauración y accesibilidad por medios digitales. Las características técnicas de la copia hoy disponible son las siguientes:

- Se trata de una copia restaurada con modificaciones sustanciales

- Tiene una duración de 60 minutos

- Es en blanco y negro

- Es muda, aunque se visiona con el acompañamiento superpuesto de música de piano

En relación al contenido de la película, cabe destacar que está realizada con una perspectiva que oscila entre la propaganda, el folclore y la etnografía. En su transcurso se muestran, siempre desde una mirada positiva, diferentes instituciones dedicadas a la infancia. Cumplía así con el encargo de la Junta, en el que se especificaba que debía proporcionar una "honrosísima visión de la caridad y la ciencia valencianas", según palabras del inspirador de la iniciativa, el entonces conocido pediatra Alejandro García Brustenga. Sobre la recepción de la película, añadir que, según los restauradores, el pase del documental fue un éxito en París, proyectándose en más sesiones de las previstas.

Para el estudio que aquí nos ocupa, nos hemos centrado en el análisis de cuatro de los siete apartados que configuran el film. Estos son:

- El correspondiente a los primeros cuidados del niño/niña

- Los sanatorios

- El laboratorio de psicología y orientación profesional

- La atención al niño/niña con dificultades de aprendizaje

\section{EL FILM "EL SEGELL PRO-INFÀNCIA"}

Como ya hemos explicado, a inicios del siglo $\mathrm{XX}$ aparecen diversos programas que buscan mejorar las condiciones de vida y de salud de los niños y niñas. Es en este contexto que surge la iniciativa del Sello Pro-Infancia. Dicha campaña aparece en 1933 con el fin de promover la asistencia a la infancia y disminuir la mortalidad infantil. La actividad nace haciéndose eco de las iniciativas promovidas inicialmente en Dinamarca por el cartero EïnerHolböll en 1903 e implantadas posteriormente en Suecia (1905), Holanda (1906), Alemania (1907) o Estados Unidos (1907) (ALIER, 1937, p. 35). 
En este caso la iniciativa fue amparada por la Generalitat de Catalunya que creó una institución bajo el nombre de Segell Pro-Infància con funcionalidad autónoma y que aglutinó a médicos, personas del mundo intelectual y políticos (PERDIGUERO Y CASTEJÓN, 2006).

Según manifestaban los promotores de la campaña, ésta estaba destinada a:

A difundir en toda Catalunya las recomendaciones de higiene social e infantil, por medio de la imagen, radio, films, prensa, folletos, conferencias, etc. hasta que el pueblo esté saturado de dichas recomendaciones y las cumpla de la manera más natural, sin esfuerzo, incorporadas en el rimo de su vida. (TRIAS MAXENCHS, 1937, p. 511).

Las campañas publicitarias del sello fueron bastante amplias y se llevaron a cabo distintas actividades en todo el territorio. Se realizaron carteles, festivales, revistas, conferencias, canciones, etc. La grabación del film que aquí nos ocupa fue otra de las formas de publicidad que se utilizaron.

Por los estudios de recepción cinematográfica del período, sabemos que el film se visualizó en diferentes salas del territorio. Sin embargo, las recaudaciones fueron un poco inferiores a las esperadas.

El film fue producido por la Generalitat de Catalunya entre 1934 y 1935 y el director se desconoce. Actualmente, se conservan copias del film tanto en la Filmoteca de España como en la Filmoteca de Catalunya. En ambos casos, no existe la posibilidad de reproducción, pero sí de visionado. Las características técnicas de la copia son las siguientes:

- Es un film rodado en 35 milímetros

- Tiene una duración de 6 minutos y 54 segundos

- La película está rodada en blanco y negro

- La copia es muda

En cuanto al contenido del film cabe destacar que utiliza recursos como las metáforas, iconografías, juegos de luces, entre otros para mostrarnos lo deseado y lo indeseado e intenta convencer sobre las consecuencias que puede acarrear, tanto aceptar el mensaje como no hacerlo.

\section{EL FILM "VIDAS NUEVAS"}

El documental de Julio Bravo Vidas Nuevas se enmarca dentro de las campañas del Gobierno Español que, en octubre de 1931, había creado la Sección de Higiene Social y Propaganda dentro de la Dirección General de Sanidad. En el decreto regulador de dicha sección se especifica que el objetivo radicaba en promover: "la propaganda de la higiene 
personal y pública, hoy por hoy descuidada, casi inexistente, en tanto que es un elemento de la máxima importancia en el desarrollo de un programa sanitario-médico" (Decreto de creación de la Sección de Higiene Social y Propaganda, 1931).

Justo el 2 de mayo de 1933, en la Gaceta de Madrid salió publicada la resolución del concurso para proveer la plaza de Jefe de Sección de Propaganda Sanitaria que se adjudicaría a Julio Bravo Santfeliu, médico dermatólogo del cuerpo oficial de médicos de la lucha antivenérea de Madrid que dedicó parte de su actividad a provocar cambios en los hábitos higiénicos a través de los medios publicitarios.

Solamente cinco meses después de ser nominado como director de propaganda se publicó otra orden ministerial por la cual se obligaba“a las personas o entidades explotadoras de locales dedicados al cinematógrafo [...] a proyectar en cada uno de los respectivos programas, las películas que a tal efecto les sean entregadas por la Subsecretaria de Sanidad y Beneficencia” (ORDEN DEL MINISTERIO DE GOBERNACIÓN, 1933).

Entre las diferentes actividades promovidas por Julio Bravo está la producción de este documental que, aun siendo producido en 1936, antes de estallar la Guerra Civil, el régimen franquista se lo apropiaría, atribuyendo su producción al Ministerio de Gobernación y datándolo en los años 40 (PERDIGUERO, 2008).

A día de hoy, se conserva una copia del documental en la Filmoteca de Catalunya, y del mismo disponemos una copia con permiso de reproducción.

En cuanto a las características técnicas del film, señalar que:

- Fue realizado por la Dirección General de Sanidad y patrocinado por la Casa Bayer.

- Su duración es 17 minutos.

- Está rodado en blanco y negro.

- Es sonoro (a diferencia de los anteriores).

El guion fue realizado por el mismo Julio Bravo con la colaboración de Miguel Echegaray (director de la Escuela de Puericultura por la lucha contra la mortalidad infantil de Barcelona). El documental tiene tres partes, una primera introductoria, una segunda con consejos a tener en cuenta durante el embarazo y la tercera sobre el cuidado de los recién nacidos (PERDIGUERO, 2008). 


\section{EL ANÁLISIS FORMAL DE LOS FILMS}

A continuación presentamos el estudio comparativo que hemos realizado de los films concretado en el análisis formal y el del contenido. Para realizar el análisis formal de las producciones cinematográficas señaladas nos hemos centrado primeramente en las características técnicas.

Sobre las mismas, es importante señalar que aunque los tres films distan solamente de 8 años, es en este momento cuando se está realizando el paso del cine mudo al cine sonoro. Un cambio que, en el caso español y en lo que refiere a los reportajes se realizó con más lentitud que en otros contextos. Así, aunque a partir de la década de los años 30 las producciones ya solían integrar el audio, en España, los noticiarios, documentales y pequeñas producciones domésticas todavía se producían en formato mudo. Una de las razones exhibidas es la correspondiente a la carencia de los reproductores adecuados en las salas de visionado.

Vidas Nuevas, con la incorporación de audio, se perfila como un documental innovador en cuanto a la forma adquirida. No en vano, Julio Bravo había sido un claro defensor del cine sonoro como medio educativo y de propaganda. Defensa que era explícita en algunas de sus publicaciones como podemos ver en las siguientes palabras: "Para la gran propaganda, para la propaganda intensiva, extensiva y eficaz, para hablar a las multitudes, no hay método más adecuado que el que ofrece el cine sonoro" (BRAVO, 1932, p. 476).

Además de la innovación que suponía la incorporación de este avance técnico, las formas finales revisten de otra diferencia fundamental, el metraje: de los casi 60 minutos de Valencia protectora de la Infancia, pasamos a los casi 7 minutos del Segell Pro-Infancia o los 17 minutos de Vidas Nuevas.

A priori, esta variación de minutaje debería suponer diferencias en los contenidos pero, según nuestro análisis, éstas no se explican por la distinta duración, sino por las finalidades de los films, así como las rutas expositivas que utilizan y sus secuencias y planos. En vistas de ello, y haciéndonos eco de las aportaciones de la psicología social y de publicitaria, nos hemos centrado en estos aspectos.

Sobre las finalidades, apuntar a que Valencia protectora de la Infancia es una producción que se realizó con claros fines de propaganda de la labor realizada por la administración e instituciones de caridad en la ciudad de Valencia. El rótulo laudatorio sobre la acción de las instituciones Valencias es claro.

El Segell Pro-Infància también se produjo con fines propagandísticos. Sin embargo, en esta ocasión, el fin propagandístico se mezclaba con las finalidades recaudatorias y 
educativas. En cuanto a la vertiente educativa, el mismo secretario del sello, el Sr. Trias Maxencs, destacaba la necesidad de que todas las personas tomasen consciencia de nuevos hábitos de salud para, de esta forma, prevenir enfermedades que podrían tener consecuencias, muchas veces mortales. El mismo autor consideraba que:

El sello por si mismo tiene ya un sentido educativo, porque con él se produce una corriente de solidaridad social y se recuerda la necesidad de ir a la ayuda de los que lo necesitan, así como recordar a todos que con la higiene se trabaja contra la mortalidad y se labora para un mejor bienestar de la humanidad. (TRIAS MAXENCHS, 1937, p. 509).

La creación de Vidas Nuevas respondía a una clara intención educativa: con la misma se pretendía promover los cambios de hábitos higiénicos.

Las tres producciones, por lo tanto, respondían a finalidades distintas: la exposición, la recaudación y la formación de conciencias y, como consecuencia de ello, utilizaban mensajes distintos. También eran divergentes las rutas elegidas para transmitir dichos mensajes.

Así pues, Valencia protectora de la Infancia utiliza, únicamente, rutas positivas de presentación de situaciones de atención a la infancia. Carece de datos explicativos y la narración está estructurada en base a constataciones visuales exitosas de actividades de protección. Incluso, cuando muestra las actividades del Tribunal de menores y de reeducación de niños enseña aquellos casos considerados como éxito. Señalar, además que, a pesar de no contener imágenes 'duras', es uno de los pocos documentales que muestra imágenes de niños y niñas con dificultades de aprendizaje, pero siempre lo hace con una mirada que podríamos caracterizar de afectuosa.

El Segell Pro-Infància usa la ruta de contraste entre graves situaciones actuales y futuros desoladores y ofrecer alternativas de acción que conlleva esperanza. Los mensajes que va insertando mediante los rótulos, así como las imágenes -tanto figurativas como metafóricas- van mezclando apelaciones a la emotividad y a la racionalidad, como vemos en las primeras secuencias, en las que aparecen imágenes de calles sucias, niños y niñas con problemas de nutrición y salud, la imagen impactante de la muerte representada con una guadaña y un reloj que va segando vidas, acompañadas de los datos numéricos.

Por último, Vidas Nuevas, utiliza fundamentalmente mensajes de esperanza construidos con una combinación de imágenes que apelan a la emotividad y un discurso oral y visual racional. Mezcla que queda claramente ilustrada en el fragmento donde se ilustra un gráfico estadístico para dar más impacto al mensaje de que la leche materna garantiza más la supervivencia de los bebés que la leche infantil preparada. A diferencia del anterior film, sin 
embargo, en éste no se presentan imágenes de especial dureza, aunque sí se muestren escenas de contraste sobre acciones negativas y positivas.

Analizando las tres composiciones, podemos observar como las rutas van haciéndose cada vez más complejas y de más difícil análisis directo para quienes estaban visionando estos films en sala.

Por otra parte, también son varios las Secuencias y planos utilizados. Los planos utilizados en Valencia protectora de la Infancia son en su mayoría panorámicos que, o bien muestran vistas de los edificios, o bien en muestras escenas grupales. Es una excepción el enfoque de los planos que se realizan sobre las actividades del "doctor Gómez Ferrer". Estos son mayoritariamente primeros planos que enfocan muy específicamente a las dos personas implicadas en las escenas o en las actividades que desarrollan.

En cuanto a los planos del Segell Pro-Infància, son habitualmente planos panorámicos con escenas grupales. Los planos de detalle solamente se encuentran en las configuraciones metafóricas. Asimismo, se hace un uso simbólico del blanco y negro.

Por otra parte, en Vidas Nuevas, los planos son más detalle, prestando mucha atención en mostrar claramente todo el proceso que se quiere enseñar, sólo siendo panorámicos las escenas de apertura del reportaje. Indicar, además, que en todo el film se hace un uso muy contrastado del blanco y negro.

Podríamos establecer, por lo tanto, que se va recurriendo cada vez más al detalle como forma para poder exhibir con más precisión los mensajes que se querían mostrar.

\section{EL ANÁLISIS DEL CONTENIDO}

Procediendo al análisis de contenidos, observamos que cada uno de los films analizados contiene un importante número de mensajes directos e indirectos que permiten constatar cuáles era consideradas las mejores prácticas de atención a la infancia en el período. Por ello, del visionado podemos sacar conclusiones sobre algunos aspectos que consideramos relevantes.

Entre las mismas, destaca el hecho que en todas las ocasiones se observa claramente la convicción que el desarrollo infantil tiene dos enclaves claros: el físico y el mental. En numerosas ocasiones, la atención sanitaria se presenta combinada con la atención al aprendizaje. Las escenas de niños y niñas aprendiendo en hospitales y sanatorios son muestras de ello. 
Por otra parte, destaca que, en cuanto a las cuestiones psicológicas, éstas se presentan como secundarias en relación a la atención médica. La pequeña medalla de "No me beses" que lleva el bebé de Vidas Nuevas, es claro indicativo de ello, pues, por razones profilácticas, se prefiere la distancia al contacto físico. Así mismo, también en el mismo film, cuando se describen las actividades del psiquiatra, y aunque haga referencia al uso del psicoanálisis y la hipnosis para la reeducación, las actividades son de carácter eminentemente físico. Es por ello que en los tres documentales se pueden caracterizar fácilmente a las instituciones de atención, la identificación de los responsables de la salud y las características de la atención sanitaria promovida.

En cuanto a las instituciones de atención, debemos comprender que, en este momento, se estaba construyendo todo un sistema de atención a la infancia que, con las diferencias impuestas por las circunstancias y los cambios de los modos de pensar, perduraría a lo largo del siglo XX.

A pesar de que en los documentales solamente se presentan instituciones consideradas de vanguardia, las mismas son representativas de los servicios que se consideraban necesarios. Entre éstos, aparecen de manera insistente:

- Servicios de atención a la maternidad o Servicios pre maternales y Escuelas Maternales

- Servicios de atención médica a la primera infancia o consultorios infantiles y hospitales infantiles

- Servicios de atención a la infancia desprotegida o casas de asilo

- Espacios para la primera infancia o guarderías, casas de lactantes, jardines de infancia

- Escuelas

- Servicios para el restablecimiento de la salud o sanatorios y colonias infantiles

- Servicios para la atención a la infancia con dificultades de aprendizaje o centros para la enseñanza de ciegos y sordomudos

- Servicios de atención a la infancia con problemas con la justicia o centros de reeducación

A través del análisis de los sujetos en acción podemos observar que, a pesar de que siempre los responsables de la salud y aprendizaje infantil son los adultos, en los films hay algunas diferencias que cabe destacar. 
En Valencia protectora de la Infancia aparecen como principales responsables, las madres y familiares y en el caso de niños y niñas tuteladas, los y las religiosas, gozando, todos ellos, de la colaboración de los profesionales médicos y enfermeras. Siendo los médicos los que tienen la voz científica, aconsejan y dan órdenes y las enfermeras quienes se ocupan de enseñar cómo atender a los niños y niñas.

En cambio, en el Segell Pro-Infància, todos los adultos y adultas (familias, profesionales y ciudadanos en general) son los responsables de la salud de los niños y niñas. Aunque tengan funciones distintas, en el film es explícita la apelación a que toda la ciudadanía ha de contribuir a mejorar la calidad de vida de la infancia. Bien sea cambiando hábitos, bien sea contribuyendo a la higiene colectiva, bien sea aportando dinero a las instituciones que se ocupan de los pequeños y pequeñas.

Por último, en Vidas Nuevas, se adjudica la responsabilidad principal de la salud infantil a los padres por los temas de procreación, y en especial a las madres para los cuidados, llegando incluso a culpar a éstas si no actúan como se les aconseja desde los médicos. En este sentido, aunque aparece como en Valencia protectora de la Infancia la labor de acompañamiento de los médicos y enfermeras, estos tienen una labor subsidiaria.

Sobre las características de la atención sanitaria promovida en los distintos documentales vemos la atención sanitaria caracterizada por dos funciones principales que complementan la labor educativa. En primer lugar, encontramos la revisión, desempeñada fundamentalmente por médicos y enfermeras. En el transcurso de las escenas van apareciendo distintas imágenes que refuerzan la idea del control pediátrico (más o menos profesional) realizado por las distintas instituciones sanitarias y educativas. Por otra parte el tutelaje y la labor de acompañar los procesos de crecimiento de los niños y niñas se ve expresada en el modelaje que realizan las enfermeras.

Implícitamente, en los documentales de Valencia protectora de la Infancia y de Vidas Nuevas se manifiesta una desconfianza con la cultura popular de cuidado de los niños y niñas. De hecho, ello coincide con las normativas aprobadas durante el primer franquismo aún en tiempos de guerra, en las que se adjudicaba a la 'incultura popular' la situación deplorable de la infancia. Así, leemos en el Decreto de creación de la Oficina Central de Divulgación y Propaganda (1938, p. 7610) las siguientes afirmaciones:

Es hoy axiomático en Sanidad que uno de los factores más importantes en la lucha contra las deficiencias biológicas, los estados de inferioridad física, las enfermedades infecciosas y cuanto abarca y trata de combatir la Higiene pública, es la incultura popular sobre estas materias; y ello es cierto, al extremo de que en algunas ramas sanitarias, como la Puericultura, dicha ignorancia constituye por sí 
sola la causa constante y poderosa de qué todavía persista una lacra tan dolorosa como es la mortalidad infantil en proporciones incompatibles con el engrandecimiento nacional. Por incuria, por ignorancia, porque no se ha formado una opinión pública, porque a los problemas sanitarios acaso se les ha dado un sello de academia divorciado del alcance popular, hoy gran parte de nuestros niños mueren en la primera infancia, se desarrollan mal en la segunda, al llegar a la juventud se pierden físicamente muchos valores, no hay luego adaptación entre el físiologismo y la capacidad de trabajo, extiéndese los contagios de las enfermedades evitables, y a las necesidades del saneamiento contéstase con la desidia y la incomprensión.

Como resultado de esta desconfianza, proliferan, en los dos documentales, las imágenes para enseñar a vestir, limpiar y dar de comer a los más pequeños y que están creadas con fines claramente didácticos.

Por último, y ya concluyendo, añadir que a estas dos funciones se le añade otra función en el caso de Valencia Protectora de la Infancia. Ésta es la de la experimentación psicológica con jóvenes que viene representada en las, cuanto menos impactantes, escenas del Laboratorio de Orientación psicológica y profesional.

\section{BIBLIOGRAFÍA}

ALIER, Antoni. Segell Pro Infància. Nova Iberia, 2, p.35-36, 1938.

BRAVO, Julio. Algunas consideraciones acerca del porvenir del 'cine' sonoro en propaganda sanitaria. Revista de Sanidad e Higiene Pública, 7, p. 475-478, 1932.

DECRETO de creación de la Sección de Higiene Social y Propaganda. Gaceta de Madrid, 287, p. 256, 14 de octubre de 1931.

DECRETO de creación de la Oficina Central de Divulgación y Propaganda. Boletín Oficial del Estado, 586, pp. 7610-7611, 31 de mayo de 1938.

MOLERO, Jorge. La tuberculosis como enfermedad social en los estudios epidemiológicos españoles anteriores a la guerra civil. Dynamis: Acta Hispanica ad Medicina e Scientiarumque. Historiam Illustrandam, 9, p. 185-223, 1989.

ORDEN del Ministerio de Gobernación. Gaceta de Madrid, 281, p. 214, 8 de octubre de 1933.

PERDIGUERO, Enrique. La salut a través del smitjans. Propaganda sanitària institucional en l'Espanya del sanysvint i trenta del segle XX. Mètode: Revista de difusió de la investigació de la Universitat de Valencia, 59, p. 60-69, 2008.

.; CASTEJÓN, Ramón. El Segell pro Infància i la propaganda sanitària. In: BATLLÓ, Josep et al. Actes de la VIII Trobada d'Història de la Ciència i la Tècnica. Barcelona: Societat Catalana d'Història de la Ciència i de la Tècnica, 2006, p. 229-236. 
TRIAS MAXENCS, Alfons. El Segell pro Infància a Catalunya. Noticiari d'activitats. La Medicina Catalana. Portantveu de l'Occitània Mèdica, 43-44, p. 506-511, 1937. 